\title{
Cervical cancer in women under 30 years of age in Norway: a population-based cohort study
}

Brit Helene Gravdal' ${ }^{1}$ Stefan Lönnberg ${ }^{2}$, Gry Baadstrand Skare², Gerhard Sulo ${ }^{3}$ and Tone Bjørge ${ }^{1,2^{*}}$

\begin{abstract}
Background: We compared women with incident cervical cancer under the age of 30 with older women with regard to stage, morphology, screening history and cervical cancer mortality in a population-based cohort study.

Methods: We included data from the Cancer Registry of Norway. Incidence rates (per 100,000 women-years) were calculated and joinpoint regression was used to analyse trends. The Nelson-Aalen cumulative hazard function for risk of cervical cancer death during a 15-year follow-up was displayed. The hazard ratios (HRs) of cervical cancer mortality with 95\% confidence intervals (Cls) were derived from Cox regression models.

Results: The incidence of cervical cancer in women under the age of 30 has almost tripled since the 1950s, with the steepest increase during 1955-80 (with an annual percentage change (APC) of 7.1\% (95\%Cl 4.4-9.8)) and also an increase after 2004 (3.8\% (95\%Cl-1.3-9.2)). Out of 21,160 women with cervical cancer (1953-2013), 5.3\% were younger than 30 years. A lower proportion of younger women were diagnosed at more advanced stages and a slightly higher proportion were diagnosed with adenocarcinoma and adenosquamous carcinoma comparing women above 30 years. The cumulative risk of cervical cancer death was lower for patients under the age of 30 . However, the difference between the age groups decreased over time. The overall adjusted HR of cervical cancer mortality was 0.69 ( $95 \% \mathrm{Cl} 0.58-0.82)$ in women diagnosed under the age of 30 compared to older women.
\end{abstract}

Conclusion: There has been an increase in cervical cancer incidence in women under the age of 30. Cervical cancer in younger women was not more advanced at diagnosis compared to older women, and the cervical cancer mortality was lower.

Keywords: Cervical cancer, Young women, Population-based

\section{Background}

Cervical cancer is the fourth most common cancer in women globally and affects women of all ages [1]. It is the second most common form of cancer in women 15-44 years [2]. A nationwide cervical cancer screening programme was introduced in Norway in 1995 [3]. However, prior to organized screening, there was extensive

\footnotetext{
*Correspondence: Tone.Bjorge@uib.no

${ }^{1}$ Department of Global Public Health and Primary Care, University of Bergen, 5020 Bergen, Norway

Full list of author information is available at the end of the article
}

opportunistic screening $[4,5]$. The primary aim of the screening programme is to reduce the incidence and mortality of the disease by identifying and treating its precursor lesions before they develop into cancer [6]. The programme recommends screening every three years for women between 25 and 69 years of age. The screening programme is based on reminders and relies on centralised registration and monitoring of all cervical cytology, human papillomavirus (HPV) tests, cervical histology and treatment of cervical intraepithelial neoplasia (CIN) lesions and cancer [7]. In 2015, the randomised 
implementation of HPV primary screening in women aged 34-69 commenced in four counties in Norway, replacing cytology [8]. Since 2019, HPV primary screening is gradually being introduced in the remaining Norwegian counties.

In Norway, a reduction of $68 \%$ in total cervical cancer incidence due to screening has been estimated [9]. However, there has been an increase in cervical cancer incidence in women under 30 years over the past $20-25$ years in Norway and other European countries, such as the UK $[7,10]$. The reasons for the increase are unclear but may include changes in sexual behavior and the burden of associated sexually transmitted infections, including HPV [10, 11].

In a study from the UK, cervical cancer in young women (under 25 years) tended to be more aggressive and advanced at the time of diagnosis (stage $1 \mathrm{~B}+$ or worse) than if diagnosed in older women (25-29 years) [10]. Furthermore, a higher proportion of younger women were diagnosed with adenosquamous carcinoma and other rarer histological types [10]. Also, the participation rates in cervical cancer screening programmes have slowly decreased in young women in many developed countries in recent years for no clear reason [12].

In this study, we aimed to compare stage, histology, screening history and subsequent cervical cancer mortality in women diagnosed with cervical cancer under 30 years of age (overall and stratified into $<25$ and 25-29 years) with those diagnosed with cervical cancer at an older age in Norway.

\section{Methods}

\section{Data sources}

The Cancer Registry of Norway (CRN) was established in 1953 and contains mandatory information on all new cancer cases and precancerous lesions. Information from clinical notifications, pathological notifications and death certificates are the main reporting sources and provide information about site, histological type and stage of disease at the time of diagnosis. The coding and classification system at the CRN is in accordance with international standards [13]. The CRN has also recorded causes of death for cancer patients (from the Cause of Death Registry [14], run by the Norwegian Institute of Public Health), available from 1960.

The Norwegian Cervical Cancer Screening Programme (NCCSP) is an integrated part of the national health care system. The CRN runs the program and receives mandatory reports from private and public pathology and microbiology laboratories. The programme keeps complete records of the results of all pap smears, histology specimens and HPV tests. Individual screening data are recorded and organized into four sub-registries: The
Cytology Register, the Histology Register, the HPV Test Register and the CIN Register, the last containing followup and treatment data. The SNOMED coding system, with some local adaptations, is used for classification (cytology and histology).

All residents in Norway are assigned a unique identification number used in all administrative and medical registries/databases. This identification number enables accurate record linkage.

\section{Study population}

This cohort study included all women diagnosed with cervical cancer (International Classification of Diseases (ICD)-10; C53) in Norway during 1953-2013 $(\mathrm{n}=21,160)$. No cases with ICD-10 code 55 were included. For 34 women who had two cervical cancer diagnoses, only the first recorded diagnosis was included.

\section{Statistical analysis}

Period of diagnosis (1953-68, 1969-83, 1984-98, and 1999-13), stage distribution (International Federation of Gynecology and Obstetrics: FIGO (1986); stages 1-4), morphology (squamous cell carcinoma, adenocarcinoma, adenosquamous carcinoma, other malignancies and unspecified morphology) [9] and screening history; smears taken from 3.5 years and up to six months prior to diagnosis (no smear, only normal smears, abnormal smears and only unsatisfactory smears), by age groups $(<25,25-29$ and $\geq 30$ years) were descriptively displayed and analysed using contingency tables. Information on screening history was available for cancers diagnosed from 1 July, 1995 onwards [15]. Chi-square tests were used to evaluate differences in distributions between age groups. A p-value below 0.05 was considered statistically significant.

Crude incidence rates (per 100,000 women-years) of cervical cancer by age group ( $<30$ and $\geq 30$ years) and age-standardised rates (World standard population), 1955-2014, were calculated separately using supporting data from the CRN (Fig. 1), taking immigration and emigration into account. The temporal trends in agestandardised rates were estimated using Joinpoint Trend Analysis Software from the National Cancer Institute (Version 4.8.0.1). We analysed time trends in incidence rates in women $<30$ and $\geq 30$ years. For the joinpoint analysis we used age-specific numbers of cervical cancer provided by the CRN, population numbers from Statistics Norway, in 12 five-year periods (1955-59, ..., 201014) and weights for age-standardisation to the World standard population from the WHO [16]. The whole period 1955-2014 was segmented by the points with trend change, and the annual percentage change (APC) in rates between the trend-change points was estimated. 


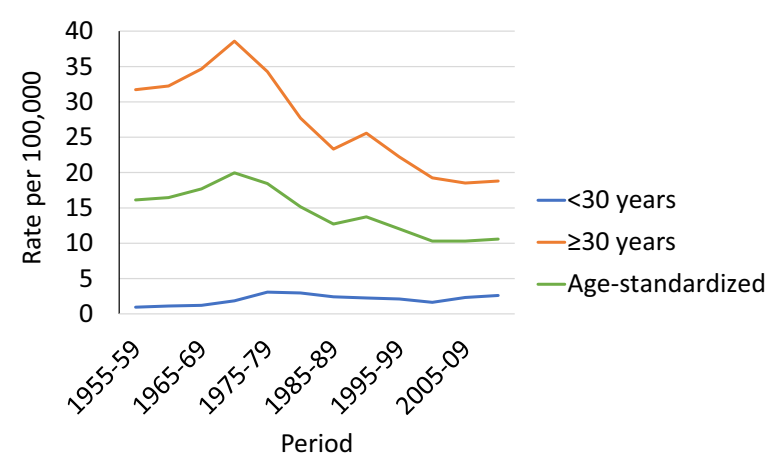

Fig. 1 Crude incidence rates (per 100,000 women-years) by age ( $<30$ and $\geq 30$ years) and age-standardised rates (World standard population) of cervical cancer, Norway, 1955-2014

Thereafter, the average annual percent change (AAPC) for the whole study period was calculated as a weighted average of the estimated APC in each segment by using the segment lengths as weights [17].

The Nelson-Aalen cumulative hazard function for risk of death from cervical cancer, with 95\% confidence intervals (CIs), during a 15-year follow-up by age $(<30$ and $\geq 30$ years) and period of diagnosis (1960-73, 1974-86, 1987-99 and 2000-13), was calculated [18, 19]. The start of follow-up was from date of diagnosis and the individuals were followed up until emigration, death, 15 years after diagnosis or end of follow-up on 31 December, 2016, whichever occurred first. Follow-up ended 15 years after diagnosis due to the relatively low number of deaths.

Hazard ratios (HRs) of cervical cancer mortality with 95\% CIs, with and without adjustment for stage (FIGO stages 1-4), morphology (squamous cell carcinoma, adenocarcinoma, adenosquamous carcinoma, other malignancies and unspecified morphology) and time of diagnosis (continuous), were derived from Cox proportional hazard regression models. We also presented estimates for specific periods of diagnosis (1960-73, 1974-86, 1987-99 and 2000-13).

The data were analysed using IBM SPSS Statistics 22 (IBM Corporation, Armonk, NY, USA) and Stata/IC 14.0 (StataCorp LP, College Station, TX, USA).

\section{Results}

Since the 1950s, the incidence of cervical cancer in women aged $<30$ increased from 0.9 per 100,000 womenyears in 1955-59 to 2.6 in 2010-14) (Fig. 1). However, the increase has not been steady. The joinpoint regression analysis identified two joinpoints, in 1980 and 2005. After a peak in the 1970s (APC in incidence was 7.1\% (95\% CI 4.4-9.8) during 1955-80), the incidence slightly decreased in 1980-2005 (APC in incidence was $-2 \%(95 \% \mathrm{CI}-3.5-0.0))$ and then increased slightly again after 2004 (APC in incidence was 3.8\% (95\% CI -1.3-9.2) during 2005-14). For the whole period 1955-2014, the AAPC in incidence was $2.3 \%$ (9\% CI 1.2-3.4). In contrast, in women aged $\geq 30$, the incidence was 31.7 in 1955-59 and declined after a peak in the early 1970 s to 18.8 in 2010-14.

The main analysis included a total of 21,160 women diagnosed with cervical cancer in Norway during 19532013. Table 1 summarises the characteristics of these women by age at diagnosis. Most women were above 30 years $(94.7 \%)$. Cervical cancer was rare in women under 25 years of age, with only 207 cases $(0.98 \%)$ in this age group. In women under 30 years, $87.0 \%$ in the age group $<25$ years and $82.4 \%$ in the age group $25-29$ years were diagnosed at stage 1 , whereas in women above 30 years, $51.8 \%$ were diagnosed at stage 1 .

In all cases, the proportion of women diagnosed with stage 1 cancer increased from $42.4 \%$ in $1953-68$ to $58.8 \%$ in $1999-2013$. The corresponding proportions in women $<30$ years were $59.7 \%$ and $81.4 \%$, respectively (Table 2). The majority of women in all age groups were diagnosed with squamous cell carcinoma, but a slightly higher proportion of women under 30 years were diagnosed with adenocarcinoma and adenosquamous carcinoma compared to women above 30 years (Table 1). For women with adenocarcinoma and adenosquamous cell carcinoma, a higher proportion were diagnosed at stage 1 (Table 3) than for women with squamous cell carcinoma. For women under 30 years with adenocarcinoma and adenosquamous carcinoma, 83.1 and $77.5 \%$, respectively, were diagnosed at stage 1 .

We only had data on screening history available for those women diagnosed from 1 July, 1995 when the national screening programme started. Overall, 60.3\% of these women did not have smears taken during the 3.5-year period preceding diagnosis; the corresponding proportion was $62.0 \%$ in women above 30 years, $38.7 \%$ in women $<25$ years and $36.8 \%$ in women $25-29$ years (Table 1). Also, a higher proportion of women in the younger age group had only normal smears before diagnosis (age $<25 ; 40.3 \%$ and age $25-29 ; 36.8 \%$ ), when compared to women above 30 years of age (25.0\%). In women under 30 years of age, $21.0 \%$ of women under 25 years and $23.5 \%$ of women $25-29$ years had abnormal smears 3.5 years before diagnosis; $11.6 \%$ in women above 30 years. Additional file 1: Table 1 (Table S1) displays similar figures for women in the target age range of the screening programme (25-69 years).

Figure 2 shows the cumulative risk of death from cervical cancer during a 15-year follow-up by age $(<30$ and $\geq 30$ years) and period of diagnosis (1960-73, 
Table 1 Characteristics of women diagnosed with cervical cancer in Norway by age, 1953-2013

\begin{tabular}{|c|c|c|c|c|c|c|c|c|c|}
\hline & \multicolumn{2}{|l|}{ All ages } & \multicolumn{2}{|c|}{ Age $<25$} & \multicolumn{2}{|c|}{ Age 25-29 } & \multicolumn{2}{|c|}{ Age $\geq 30$} & \multirow[t]{2}{*}{ p-difference } \\
\hline & $n$ & $\%$ & $\mathrm{n}$ & $\%$ & $n$ & $\%$ & $n$ & $\%$ & \\
\hline \multicolumn{10}{|l|}{ Period of diagnosis } \\
\hline 1953-68 & 5,495 & 26.0 & 13 & 6.3 & 106 & 11.6 & 5,376 & 26.8 & \\
\hline 1969-83 & 6,168 & 29.1 & 85 & 41.1 & 263 & 28.7 & 5,820 & 29.0 & \\
\hline 1984-98 & 5,089 & 24.1 & 59 & 28.5 & 290 & 31.7 & 4,740 & 23.7 & \\
\hline 1999-13 & 4,408 & 20.8 & 50 & 24.2 & 256 & 28.0 & 4,102 & 20.5 & $<0.001$ \\
\hline \multicolumn{10}{|l|}{ Stage (FIGO) } \\
\hline 1 & 11,322 & 53.5 & 180 & 87.0 & 754 & 82.4 & 10,388 & 51.8 & \\
\hline 2 & 5,236 & 24.7 & 19 & 9.2 & 103 & 11.3 & 5,114 & 25.5 & \\
\hline 3 & 2,775 & 13.1 & 3 & 1.4 & 33 & 3.6 & 2,739 & 13.7 & \\
\hline 4 & 1,487 & 7.0 & 3 & 1.4 & 9 & 1.0 & 1,475 & 7.4 & \\
\hline Unknown & 340 & 1.6 & 2 & 1.0 & 16 & 1.7 & 322 & 1.6 & $<0.001$ \\
\hline \multicolumn{10}{|l|}{ Morphology } \\
\hline Squamous cell carcinoma & 17,565 & 83.0 & 164 & 79.2 & 745 & 81.4 & 16,656 & 83.1 & \\
\hline Adenocarcinoma & 2,284 & 10.8 & 26 & 12.6 & 104 & 11.4 & 2,154 & 10.7 & \\
\hline Adenosquamous carcinoma & 374 & 1.8 & 6 & 2.9 & 34 & 3.7 & 334 & 1.7 & \\
\hline Other malignancies & 880 & 4.2 & 10 & 4.8 & 28 & 3.1 & 842 & 4.2 & \\
\hline Unspecified morphology & 57 & 0.3 & 1 & 0.5 & 4 & 0.4 & 52 & 0.3 & $<0.001$ \\
\hline Total & 21,160 & 100.0 & 207 & 100.0 & 915 & 100.0 & 20,038 & 100.0 & \\
\hline \multicolumn{10}{|l|}{ Screening history ${ }^{\mathrm{b}}$} \\
\hline No smear & 3,371 & 60.3 & 24 & 38.7 & 119 & 36.8 & 3,228 & 62.0 & \\
\hline Only normal smears & 1,445 & 25.9 & 25 & 40.3 & 119 & 36.8 & 1,301 & 25.0 & \\
\hline Abnormal smears ${ }^{c}$ & 694 & 12.4 & 13 & 21.0 & 76 & 23.5 & 605 & 11.6 & \\
\hline Only unsatisfactory smears & 78 & 1.4 & 0 & 0 & 9 & 2.8 & 69 & 1.3 & $<0.001$ \\
\hline Total & 5,588 & 100.0 & 62 & 100.0 & 323 & 100.0 & 5,203 & 100.0 & \\
\hline
\end{tabular}

a $\mathrm{p}$-values for difference: Chi-square tests between age groups

b Smears taken from 3.5 years and up to six months prior to diagnosis, available from 1 July, 1995

c Cytology diagnosis of atypical squamous cells of undetermined significance or more severe

Table 2 FIGO stage by age and period of diagnosis (\%) for women diagnosed with cervical cancer in Norway, 1953-2013

\begin{tabular}{|c|c|c|c|c|c|c|}
\hline \multirow[t]{2}{*}{ Age at diagnosis } & \multicolumn{6}{|c|}{ Period of diagnosis } \\
\hline & Stage & $1953-68$ & $1969-83$ & 1984-98 & 1999-2013 & Total \\
\hline \multirow[t]{4}{*}{$<30$ years } & & $(n=119)$ & $(n=348)$ & $(n=349)$ & $(n=306)$ & $(n=1,122)$ \\
\hline & 1 & 59.7 & 88.5 & 87.7 & 81.4 & 83.2 \\
\hline & $2+$ & 38.7 & 10.1 & 10.9 & 16.7 & 15.2 \\
\hline & Unknown & 1.7 & 1.4 & 1.4 & 2.0 & 1.6 \\
\hline \multirow[t]{4}{*}{$\geq 30$ years } & & $(n=5,376)$ & $(n=5,820)$ & $(n=4,740)$ & $(n=4,102)$ & $(n=20,038)$ \\
\hline & 1 & 42.0 & 53.4 & 56.5 & 57.1 & 51.8 \\
\hline & $2+$ & 56.2 & 45.3 & 42.6 & 40.2 & 46.6 \\
\hline & Unknown & 1.8 & 1.3 & 0.8 & 2.7 & 1.6 \\
\hline
\end{tabular}

1974-86, 1987-99 and 2000-13). The cumulative risk of death from cervical cancer decreased with calendar time for women both under and above 30 years of age. However, the difference between the age groups decreased. The cumulative risk of death from cervical cancer after
15 years of follow-up was higher for women $\geq 30$ years than for women $<30$ years in all four time periods that were studied.

In the Cox regression analysis of cervical cancer mortality (1960-2013), the women were followed for an 
Table 3 FIGO stage by age at diagnosis and morphology (\%) for women diagnosed with cervical cancer in Norway, 1953-2013

\begin{tabular}{|c|c|c|c|c|c|c|c|}
\hline \multirow[t]{2}{*}{ Age at diagnosis } & \multirow[t]{2}{*}{ Stage } & \multicolumn{6}{|l|}{ Morphology } \\
\hline & & $\begin{array}{l}\text { Squamous cell } \\
\text { carcinoma }\end{array}$ & Adenocarcinoma & $\begin{array}{l}\text { Adenosquamous } \\
\text { carcinoma }\end{array}$ & Other malignancies & $\begin{array}{l}\text { Unspecified } \\
\text { morphology }\end{array}$ & Total \\
\hline \multirow[t]{4}{*}{$<30$ years } & & $(n=909)$ & $(n=130)$ & $(n=40)$ & $(n=38)$ & $(n=5)$ & $(n=1,122)$ \\
\hline & 1 & 84.5 & 83.1 & 77.5 & 63.2 & 60.0 & 83.2 \\
\hline & $2+$ & 14.6 & 13.1 & 22.5 & 28.9 & 0.0 & 15.2 \\
\hline & Unknown & 0.9 & 3.8 & 0.0 & 7.9 & 40.0 & 1.6 \\
\hline \multirow{4}{*}{$\geq 30$ years } & & $(n=16,656)$ & $(n=2,154)$ & $(n=334)$ & $(n=842)$ & $(n=52)$ & $(n=20,038)$ \\
\hline & 1 & 51.2 & 61.5 & 56.6 & 39.9 & 21.2 & 51.8 \\
\hline & $2+$ & 47.5 & 36,4 & 42.8 & 53.0 & 69.2 & 46.6 \\
\hline & Unknown & 1.3 & 2.1 & 0.6 & 7.1 & 9.6 & 1.6 \\
\hline
\end{tabular}
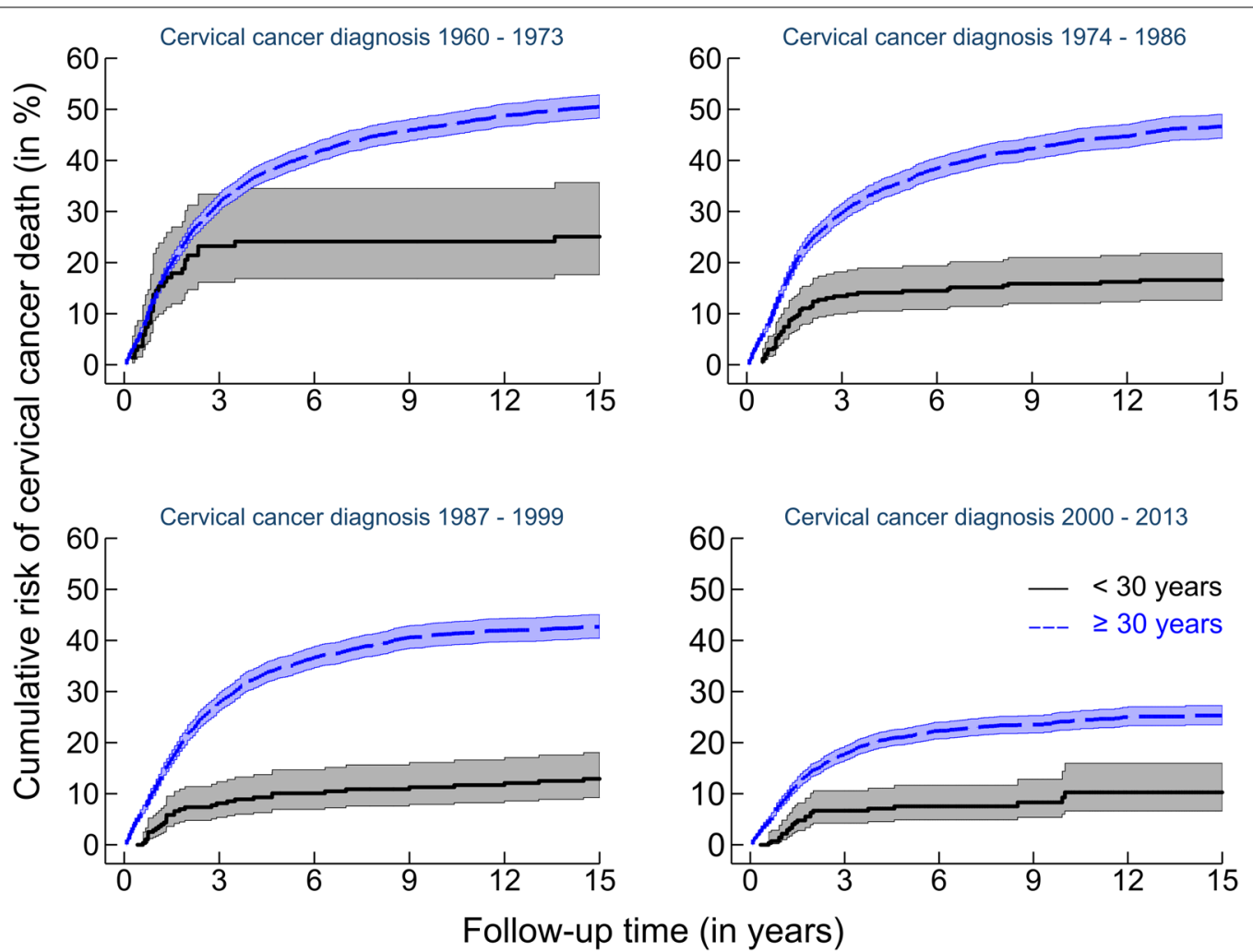

Fig. 2 Cumulative risk of death* from cervical cancer $\#$, with 95\% confidence intervals, during 15 years of follow-up by age $(<30$ and $\geq 30$ years) and period of diagnosis (1960-73, 1974-86, 1987-99 and 2000-13). * Nelson-Aalen cumulative hazard function, unadjusted estimates [18, 19]. \# 5,980 cervical cancer deaths

average of 8.7 years (range; $0-15$ years), constituting 163,500 women-years. During follow-up, 5,980 cervical cancer deaths were identified. The overall unadjusted and adjusted HRs of cervical cancer mortality were 0.38 (95\%CI 0.32-0.45) and 0.69 (95\% CI 0.58-0.82), respectively, in women diagnosed under the age of 30 compared to older women (Additional file 2: Table S2). The HRs (adjusted for stage and morphology) for the diagnosis periods 1960-73, 1974-86, 1987-99 and 2000-13 were 0.78 (95\%CI $0.55-1.13), 0.74$ (95\%CI $0.56-0.97$ ), 0.56 (95\%CI $0.40-0.80)$, and 0.66 (95\% CI $0.43-1.01)$, respectively. 


\section{Discussion}

The incidence of cervical cancer in women under 30 years of age has almost tripled since the 1950s, while decreasing overall. Nevertheless, only a small proportion of women diagnosed with cervical cancer were under 30 years of age. In our study, cancers in younger women were of earlier stage, and only a slightly higher proportion of women had adenocarcinoma and adenosquamous carcinoma compared to women above 30 years of age. Mortality from cervical cancer was lower for women under the age of 30 even after adjusting for stage. The screening history of women with cervical cancer under the age of 30 differed from those older at the time of diagnosis. A larger proportion of the younger women with cancer had preceding screening tests, both normal and abnormal. This may reflect poorer effectiveness of screening in younger age groups, as has been suggested by a number of past publications [20-22].

One of the strengths of this study was its populationbased design, including all women with cervical cancer in Norway since the 1950s. Our data set did not include information on hysterectomy. Due to the missing information on hysterectomy, incidence rates particularly among women above 30 years, are likely underestimated as the rates of hysterectomy increase with age. However, the rates of hysterectomy are relatively low in Norway compared to other Western countries [23-25].

Another limitation of the study was the relatively low number of cervical cancer cases in women in the youngest age groups. Also, when examining the screening history in women above the age of 25 , we were unable to separate the cytology tests following an invitation to screening from those taken in response to symptoms. In the NCCSP, women are invited to be screened from the age of 25. However, the results of all smears (in all age groups) are recorded. Since women under 25 years of age were not part of the national screening programme for the entire period, self-selection for screening may be more pronounced in this age group and could be influenced by factors such as the use of contraception and associated visits to health care providers, the healthy screenee effect, as well as symptoms.

The cervical cancer screening programme from 1995 with written invitations for pap smears every third year increased coverage of the target population [26]. For women 25-39 years of age there was a decrease in coverage until 2012. However, from 2012 onwards, increased coverage has been noted, particularly in women aged 25-34 years. This could be attributable to media coverage and projects aimed at increasing screening attendance, such as the "Sjekk deg-kampanjen" ran by the Norwegian Cancer Society [7].
A study from Canada published in 2001 [27] concluded that the incidence of invasive cervical adenocarcinoma and adenosquamous carcinoma had been steadily increasing in women 20-49 years of age. Another study from the UK published in 2011 showed that the incidence of cervical cancer in women 20-29 years of age increased significantly after 1992 [11]. On the contrary, a US study (2017) concluded that the incidence of invasive cervical cancer in younger women aged 21-25 was very low and declined significantly between 2000 and 2013 [28]. However, among 24-25-year-olds the incidence remained constant. Our study showed that the cervical cancer rate in women under the age of 30 has almost tripled since the 1950s. However, the incidence of cervical cancer in women both above and under 30 years peaked in the 1970s when opportunistic screening became widespread, with a further decline after the screening programme started. Overall, the proportion of women diagnosed at stage 1 increased over time, and the proportion also increased in women diagnosed under 30 years of age.

A study from the UK published in 2013 concluded that cervical cancer in young women was rare and that only a small group of women 20-29 years of age had been diagnosed with cervical cancer before the age of 25 [10]. Similarly, in our data, only around $1 \%$ of the cancers were diagnosed before the age of 25. Like the UK study, our study also showed that a clear majority of women diagnosed at $<30$ years were diagnosed at stage 1 . The same study from the UK concluded that cervical cancer in young women (aged 20-24 years) tended to be more advanced and was often of a rarer histological type than cancers in older women [10]. In our study, a slightly higher proportion of women in the younger age groups (under 30 years) were diagnosed with either adenocarcinoma or adenosquamous carcinoma, but the cancers in general did not tend to be more advanced. Also, for younger women with adenocarcinoma or adenosquamous carcinoma the majority were diagnosed at stage 1 .

A Canadian study from 2012 showed the link between invasive cervical cancer and mortality in young women 15-29 years of age. The study concluded that both the disease and mortality among these women were rare, and had declined during the study period (1970-2007) [29]. Also, an earlier Hungarian study showed no differences in survival among the different age groups, and concluded that cervical cancer in young women was not more aggressive than in other age groups [30]. A further study from England (2012) found that $91 \%$ of younger women with cervical cancer were diagnosed at stage $1 \mathrm{~A}$ or $1 \mathrm{~B}$ and had an excellent prognosis [31]. All these studies support the results of our study, showing a lower cervical cancer mortality for younger women, when compared to older women. The absolute difference in the 
cumulative risk of death from cervical cancer between the two age groups in the current study decreased with calendar time, particularly in the periods since 1987. This is probably due to the much stronger impact of the organised screening programme on both incidence and mortality in the age groups above 30 years.

There are still varying opinions regarding the appropriate age to start cervical screening. European guidelines recommend that screening should start from 25-30 years [32]. Australia's programme starts from age 18 [33], whereas the screening programmes in Finland and The Netherlands start at the age of 30 [34]. Studies have concluded that screening below the age of 25 leads to significant over-treatment with an uncertain impact on cervical cancer incidence and mortality [33, 35]. A study from the UK also concluded that the increase in cervical cancer in young women cannot be attributed to the lack of screening of women aged 20-24 years [31].

In 2009, HPV vaccination was introduced in the Norwegian national vaccination programme for girls in primary school and also included boys from autumn 2018 [36]. It is too early to quantify the long-term effects of the vaccination in Norway, but it is expected that the incidence of cervical cancer in vaccinated women will decrease rapidly. Both vaccines used in Norway have demonstrated good efficacy against the high-risk HPV types 16 and 18, responsible for an estimated $73 \%$ of cervical cancer cases in Europe $[37,38]$. HPV vaccination will likely affect the incidence of cervical cancer overall due to herd immunity, particularly given the high vaccination coverage in Norway.

\section{Conclusions}

Even though only a relatively small number of cervical cancers occurs in women under 30 years of age, rates in this age group have almost tripled in Norway since the 1950s. Cancer in young women does not tend to be more advanced at diagnosis, compared to older women. Also, the mortality from cervical cancer appears to be lower for women in the younger age groups. While the effectiveness of screening may be age-dependent, hopes are raised for an eventual decrease in cervical cancer burden across all age groups due to HPV immunisation through the Norwegian national vaccination programme from 2009 for all girls born after 1996.

\section{Abbreviations}

Cl: Confidence interval; CIN: Cervical intraepithelial neoplasia; CRN: Cancer Registry of Norway; FIGO: International Federation of Gynecology and Obstetrics; HPV: Human papillomavirus; HR: Hazard ratio; ICD: International Classification of Diseases; NCCSP: Norwegian Cervical Cancer Screening Programme.

\section{Supplementary information}

The online version contains supplementary material available at https://doi. org/10.1186/s12905-021-01242-3.

Additional file 1.Table S1. Characteristics of women aged 25-69 years diagnosed with cervical cancer in Norway by age, 1953-2013.

Additional file 2. Table S2. Hazard ratios (HRs) of cervical cancer mortality (with 95\% Cls) overall and by period of diagnosis, with and without adjustment for stage and morphology.

\section{Acknowledgements}

Not applicable.

\section{Authors' contributions}

SL, GBS and TB conceived the study. BHG wrote the first draft of the manuscript. TB performed the statistical analyses. All authors (BHG, SL, GBS, GS and TB) conceptualised the ideas, interpreted the findings and reviewed the drafts of the manuscript. All authors read and approved the final manuscript.

\section{Funding}

No specific funding was received for this study.

Availability of data and materials

The datasets analysed during the current study are not freely available due to national regulations.

\section{Declarations}

Ethics approval and consent to participate

The study and the researchers were approved by the Regional Committee for Medical and Health Research Ethics of Western Norway (REK ref. number 2014/1918). We also obtained permission to use the data from the data owners.

\section{Consent for publication}

Not applicable.

Competing interests

The authors declare no conflicts of interest.

\section{Author details}

${ }^{1}$ Department of Global Public Health and Primary Care, University of Bergen, 5020 Bergen, Norway. ${ }^{2}$ Cancer Registry of Norway, Oslo, Norway. ${ }^{3}$ Norwegian Institute of Public Health, Bergen, Norway.

Received: 27 October 2019 Accepted: 24 February 2021

Published online: 18 March 2021

References

1. Bray F, Ferlay J, Soerjomataram I, Siegel RL, Torre LA, Jemal A. Global Cancer Statistics 2018: GLOBOCAN estimates of incidence and mortality worldwide for 36 cancers in 185 countries. CA Cancer I Clin. 2018;68(6):394-424.

2. Arbyn M, Weiderpass E, Bruni L, de Sanjose S, Saraiya M, Ferlay J, et al. Estimates of incidence and mortality of cervical cancer in 2018: a worldwide analysis. Lancet Glob Health. 2020;8:e191-203.

3. Cancer Registry of Norway. Cervical cancer screening programme Annual Report 2012 (in Norwegian). Oslo: Cancer Registry of Norway; 2014.

4. Bjørge T, Gunbjørud AB, Langmark F, Skare GB, Thoresen SØ. Cervical mass screening in Norway-510,000 smears a year. Cancer Detect Prev. 1994;18(6):463-70.

5. Pedersen K, Fogelberg S, Thamsborg LH, Clements M, Nygård M, Kristiansen IS, et al. An overview of cervical cancer epidemiology and prevention in Scandinavia. Acta Obstet Gynecol Scand. 2018:97(7):795-807. 
6. Cancer Registry of Norway. Cervical cancer screening programme: organisation. https://www.kreftregisteret.no/en/screening/cervix/org Accessed 21.02.2021.

7. Cancer Registry of Norway. Cervical cancer screening programme Annual Report 2015 (in Norwegian). Oslo: Cancer Registry of Norway; 2016.

8. Engesæter B, van Diermen HB, Hansen M, Moltu P, Staby KM, Borchgrevink-Persen $\mathrm{S}$, et al. Quality assurance of human papillomavirus (HPV) testing in the implementation of HPV primary screening in Norway: an inter-laboratory reproducibility study. BMC. 2016;16:698.

9. Lönnberg S, Hansen BT, Haldorsen T, Campbell S, Schee K, Nygård M. Cervical cancer prevented by screening: Long-term incidence trends by morphology in Norway. Int J Cancer. 2015;137(7):1758-64.

10. Castanon A, Leung VM, Landy R, Lim AW, Sasieni P. Characteristics and screening history of women diagnosed with cervical cancer aged 20-29 years. Br J Cancer. 2013;109(1):35-41.

11. Foley G, Alston R, Geraci M, Brabin L, Kitchener H, Birch J. Increasing rates of cervical cancer in young women in England: an analysis of national data 1982-2006. Br J Cancer. 2011;105(1):177-84.

12. Lancucki L, Fender M, Koukari A, Lynge E, Mai V, Mancini E, et al. A fall-off in cervical screening coverage of younger women in developed countries. J Med Screen. 2010;17(2):91-6.

13. Larsen IK, Småstuen M, Johannesen TB, Langmark F, Parkin DM, Bray F, et al. Data quality at the Cancer Registry of Norway: an overview of comparability, completeness, validity and timeliness. Eur J Cancer. 2009;45(7):1218-31.

14. Pedersen AG, Ellingsen CL. Data quality in the Causes of Death Registry. Tidsskr Nor Laegeforen. 2015;135(8):768-70.

15. Bjørge T, Gunbjørud AB, Haugen OA, Skare GB, Tropé C, Thoresen $\$ \varnothing$. Mass screening for cervical cancer in Norway: evaluation of the pilot project. Cancer Causes Control. 1995;6:477-84.

16. Ahmad OB, Boschi-Pinto C, Lopez AD, Murray CJL, Lozano R, Inoue M. Age standardization of rates: a new WHO standard. 2001.

17. Dragomirescu I, Llorca J, Gomez-Acebo I, Dierssen-Sotos T. A join point regression analysis of trends in mortality due to osteoporosis in Spain. Sci Rep. 2019;9(1):4264.

18. Aalen O. Nonparametric inference for a family of counting processes. Annals Statist. 1978;6:701-26.

19. Nelson W. Theory and applications of hazard plotting for censored failure data. Technometrics. 1972;14:945-66.

20. Landy R, Pesola F, Castanon A, Sasieni P. Impact of cervical screening on cervical cancer mortality: estimation using stage-specific results from a nested case-control study. Br J Cancer. 2016:115(9):1140-6.

21. Lönnberg S, Anttila A, Luostarinen T, Nieminen P. Age-specific effectiveness of the Finnish cervical cancer screening programme. Cancer Epidemiol Biomarkers Prev. 2012;21(8):1354-61.

22. Lönnberg S, Nieminen P, Luostarinen T, Anttila A. Mortality audit of the Finnish cervical cancer screening program. Int J Cancer. 2013;132(9):2134-40.

23. Denstad SE, Aasen S, Ostrem AM, Bakkeheim V, Fossum GH, Moen MH. [Hysterectomy at St. Olavs Hospital 1989-2014]. Tidsskr Nor Laegeforen 2017; 137(16).
24. Domingo S, Pellicer A. Overview of Current Trends in Hysterectomy. Expert Rev of Obstet Gynecol. 2009;4(6):673-85.

25. Moen MH. Different practice in hysterectomy. Tidsskr Nor Laegeforen 2004;124(6):767.

26. Nygård JF, Skare GB, Thoresen S $\varnothing$. The cervical cancer screening programme in Norway, 1992-2000: changes in Pap smear coverage and incidence of cervical cancer. J Med Screen. 2002;9(2):86-91.

27. Liu S, Semenciw R, Mao Y. Cervical cancer: the increasing incidence of adenocarcinoma and adenosquamous carcinoma in younger women. CMAJ. 2001;164(8):1151-2.

28. Beachler DC, Tota JE, Silver MI, Kreimer AR, Hildesheim A, Wentzensen $\mathrm{N}$, et al. Trends in cervical cancer incidence in younger US women from 2000 to 2013. Gynecol Oncol. 2017;144(2):391-5.

29. Popadiuk C, Stankiewicz A, Dickinson J, Pogany L, Miller AB, Onysko $J$. Invasive cervical cancer incidence and mortality among canadian women aged 15 to 29 and the impact of screening. J Obstet Gynaecol Can. 2012;34(12):1167-76.

30. Póká $R$, Juhász B, Lampé L. Cervical cancer in young women: a poorer prognosis? Int J Gynaecol Obstet. 1994;46(1):33-7.

31. Sasieni $\mathrm{P}$, Castanon A. Dramatic increase in cervical cancer registrations in young women in 2009 in England unlikely to be due to the new policy not to screen women aged 20-24. J Med Screen. 2012;19(3):127-32.

32. Ponti A, Anttila A, Ronco G, Senore C, Basu P, Segnan N et al. Cancer Screening in the European Union (2017). https://ec.europa.eu/health/sites/ health/files/major_chronic_diseases/docs/2017_cancerscreening_2ndre portimplementation_en.pdf.

33. Landy R, Birke H, Castanon A, Sasieni P. Benefits and harms of cervical screening from age 20 years compared with screening from age 25 years. Br J Cancer. 2014;110(7):1841-6.

34. Elfstrom KM, Arnheim-Dahlstrom L, von Karsa L, Dillner J. Cervical cancer screening in Europe: Quality assurance and organisation of programmes. Eur J Cancer. 2015;51(8):950-68.

35. Steen $\mathrm{R}$, Hagen $\mathrm{B}$, Hagmar B, Iversen OE, Juvkam KH, Thoresen $\mathrm{S} \varnothing$, et al. What is the optimal age to start cervix screening? Tidsskr Nor Laegeforen. 2008;128(3):339.

36. Norwegian Institute of Public Health. National surveillance of HPV vaccination programme Internet https://www.fhi.no/en/studies/hpv-follo w-up/national-surveillance-of-hpv-vaccination-programme/. Accessed 21.02.2021.

37. European Centre for Disease Prevention and Control. Introduction of HPV vaccines in European Union countries - an update. https://ecdc. europa.eu/sites/portal/files/media/en/publications/Publications/20120 905_GUI_HPV_vaccine_update.pdf (2012).

38. Harper DM, DeMars LR. HPV vaccines - A review of the first decade. Gynecol Oncol. 2017;146(1):196-204.

\section{Publisher's Note}

Springer Nature remains neutral with regard to jurisdictional claims in published maps and institutional affiliations.
Ready to submit your research? Choose BMC and benefit from:

- fast, convenient online submission

- thorough peer review by experienced researchers in your field

- rapid publication on acceptance

- support for research data, including large and complex data types

- gold Open Access which fosters wider collaboration and increased citations

- maximum visibility for your research: over 100M website views per year

At BMC, research is always in progress.

Learn more biomedcentral.com/submissions 